\title{
Rectosigmoid Adenocarcinoma
}

National Cancer Institute

\section{Source}

National Cancer Institute. Rectosigmoid Adenocarcinoma. NCI Thesaurus. Code C43584.

An adenocarcinoma arising from the rectosigmoid area. It is more frequently seen in populations with a Western type diet and in patients with a history of chronic inflammatory bowel disease. Signs and symptoms include intestinal bleeding, anemia, and change in bowel habits. According to the degree of cellular differentiation, rectosigmoid adenocarcinomas are divided into well, moderately, and poorly differentiated. Histologic variants include mucinous adenocarcinoma, signet ring cell carcinoma, medullary carcinoma, serrated adenocarcinoma, cribriform comedo-type adenocarcinoma, and micropapillary adenocarcinoma. 